\title{
Study on the Impact of Hydraulic Fracturing on Surrounding Ancillary Buildings considering SSI
}

\author{
Shishan Cheng $\mathbb{D}^{1},{ }^{1}$ Dewen Liu $\left(\mathbb{D},{ }^{1}\right.$ Sitong Fang $\mathbb{D}^{\mathrm{D}},{ }^{2}$ Qianqian $\mathrm{Wu}^{1}{ }^{1}$ Lin Liu, ${ }^{1}$ Tianming Li, \\ Tong Shu, ${ }^{1}$ and Ming Lei ${ }^{3}$ \\ ${ }^{1}$ College of Civil Engineering, Southwest Forestry University, Kunming 650000, China \\ ${ }^{2}$ College of Civil Engineering, Dalian University of technology, Dalian, 116024, China \\ ${ }^{3}$ College of Civil Engineering, Southwest Jiaotong University, Chengdu 610031, China
}

Correspondence should be addressed to Dewen Liu; civil_liudewen@sina.com and Sitong Fang; 1048084186@qq.com

Received 22 August 2021; Accepted 27 September 2021; Published 21 October 2021

Academic Editor: Haojie Lian

Copyright (C) 2021 Shishan Cheng et al. This is an open access article distributed under the Creative Commons Attribution License, which permits unrestricted use, distribution, and reproduction in any medium, provided the original work is properly cited.

\begin{abstract}
Hydraulic fracturing is a key technology in the development of unconventional oil and gas reservoirs. With the continuous industrialization and large-scale development of shale gas production in China, the workload of hydraulic fracturing is also increasing rapidly, and the induced seismic events are also increasing gradually, resulting in different degrees of damage to the surrounding ancillary buildings. In order to study the impact of hydraulic fracturing on ancillary buildings, the finite element software ABAQUS was used to establish a three-dimensional model of middle and high-rise isolated structures to simulate the earthquake triggered by hydraulic fracturing. Then, considering the SSI (soil-structure interaction) effect of soil-based structure, the nonlinear dynamic response of the structure under the action of ground motion was analyzed. Through the adoption of different types of soil and the foundation depth, the influence of various parameters is discussed. The study found that in the case of not considering SSI, basal shear force, and displacement between floors of the seismicisolation structure significantly greater than considering SSI, using hard soil layer, base shear displacement is greater than the soft soil layer and interlayer, shows that due to the effect of hydraulic fracturing, making fluid diffusion in soil, the seismic energy dissipation effect. It is also found that the period, base shear, peak displacement, and interlayer displacement of deep foundation pit are increased compared with shallow foundation pit considering SSI effect.
\end{abstract}

\section{Introduction}

Hydraulic fracturing is a technology to improve productivity by increasing the number and degree of fractures in the fluid channel between the formation and the well. The principle is to inject fluid to low permeability rock under high-pressure state, usually water, so that rock ruptures or stimulates the existing fault or crack slip. In addition to fluid, the proppant is also injected, for example, sandstone sand, stone ceramics, to maintain the newly formed crack open, and finally releases oil and gas. The purpose of hydraulic fracturing is to make fractures without fractures, change small fractures into large ones, from less fractures to more fractures, and connect multiple fractures into mesh fractures. The cracks of new or existing cracks get reactivated and will induce a large number of microseismic activity in the process of fracturing. And small disturbances affecting fault stability can activate the slip of nearby faults and induce higher intensity of natural seismic activity when these microseismic activities occur within tectonic areas such as plate boundaries or distributed deformation zones. The principle of hydraulic fracturing and seismic relationship is shown in Figure 1.

In recent years, with the wide application of horizontal well multistage fracturing technology in shale gas development, the increase in pore fluid pressure caused by hydraulic fracturing causes reactivation of existing tomography or cracks and induces higher strength earthquake activity has also increased significantly $[1,2]$. Since 2008, Sichuan Basin 


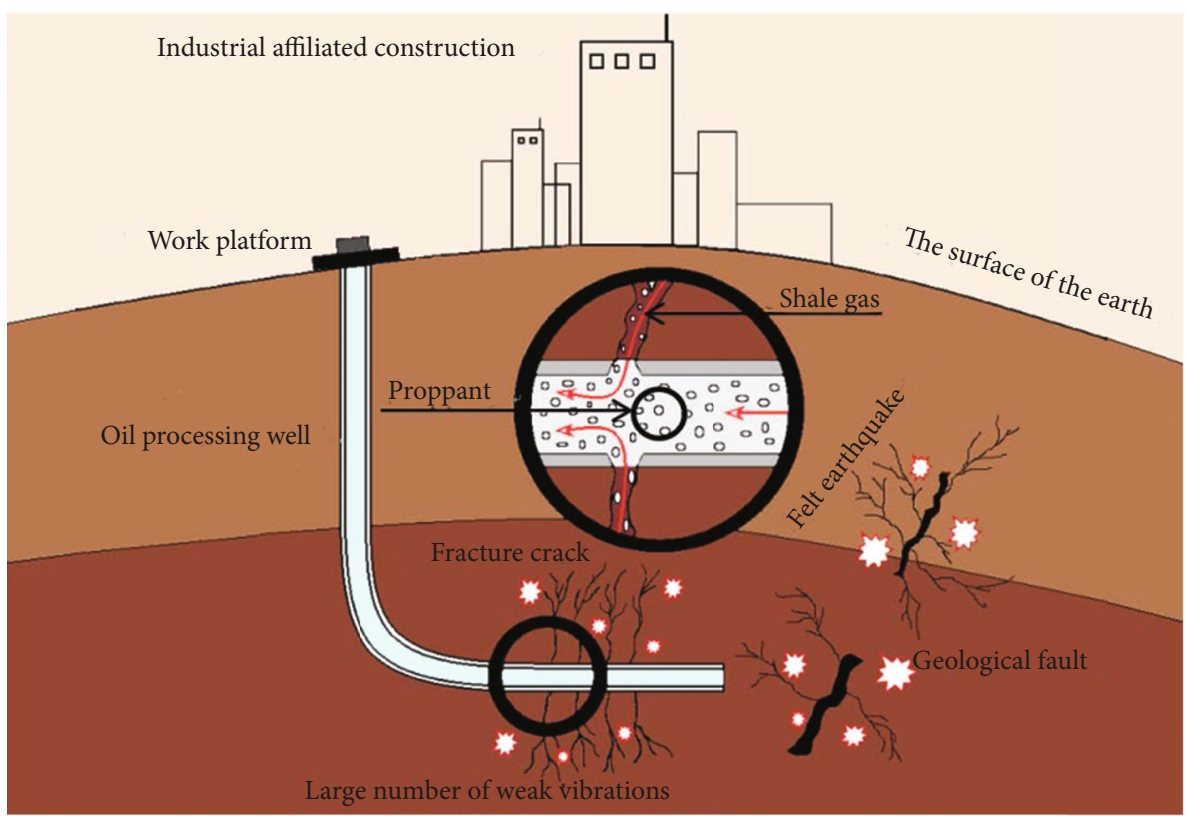

Figure 1: Schematic diagram of the relationship between hydraulic fracturing principle and seismic.

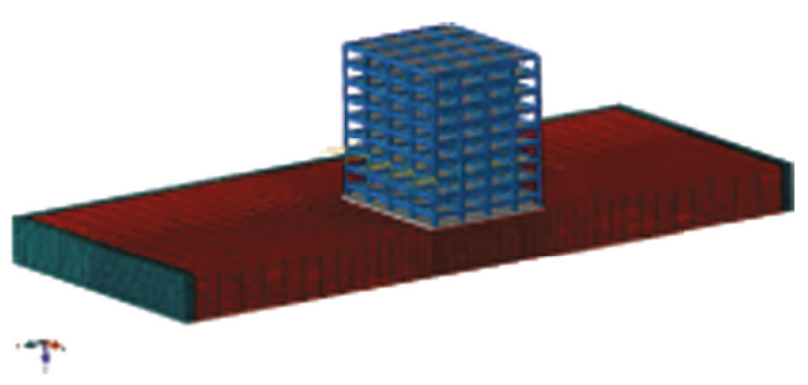

FIGURE 2: The three-dimensional numerical model of midstory isolated structure.

Table 1: Parameters of different foundation soil.

\begin{tabular}{lccccc}
\hline Number & $\begin{array}{c}\text { Young's } \\
\text { modulus } \\
(\mathrm{Pa})\end{array}$ & $\begin{array}{c}\text { Poisson's } \\
\text { ratio }\end{array}$ & $\begin{array}{c}\text { Cohesive } \\
\text { forces } \\
(\mathrm{Pa})\end{array}$ & $\begin{array}{c}\text { Friction } \\
\text { angle }\left(^{\circ}\right)\end{array}$ & $\begin{array}{c}\text { Density } \\
\left(\mathrm{kg} / \mathrm{m}^{3}\right)\end{array}$ \\
\hline 1 & $4.8 \mathrm{E} 7$ & 0.4 & 22552 & 13.5 & 1835 \\
2 & $2.73 \mathrm{E} 8$ & 0.35 & 15345 & 22.2 & 2040 \\
\hline
\end{tabular}

TABLE 2: Boundary viscous element.

\begin{tabular}{lccc}
\hline $\begin{array}{l}\text { Damping } \\
\text { ratio }\end{array}$ & $\begin{array}{c}\text { Density } \\
\left(\mathrm{kg} / \mathrm{m}^{3}\right)\end{array}$ & $\begin{array}{c}\text { Young's } \\
\text { modulus }(\mathrm{Pa})\end{array}$ & $\begin{array}{c}\text { Poisson's } \\
\text { ratio }\end{array}$ \\
\hline$\alpha=0.076$ & $1 \mathrm{E}-009$ & 0.0674 & 0.3 \\
$\beta=0.053$ & & & \\
\hline
\end{tabular}

in Southwest China has exploited shale gas. Two shale gas highly enriched areas, Changning and Fuling, have been found on the eastern edge of the southern edge of the basin. On the basis of these two blocks, demonstration area construction and expansion of mining scope have been carried

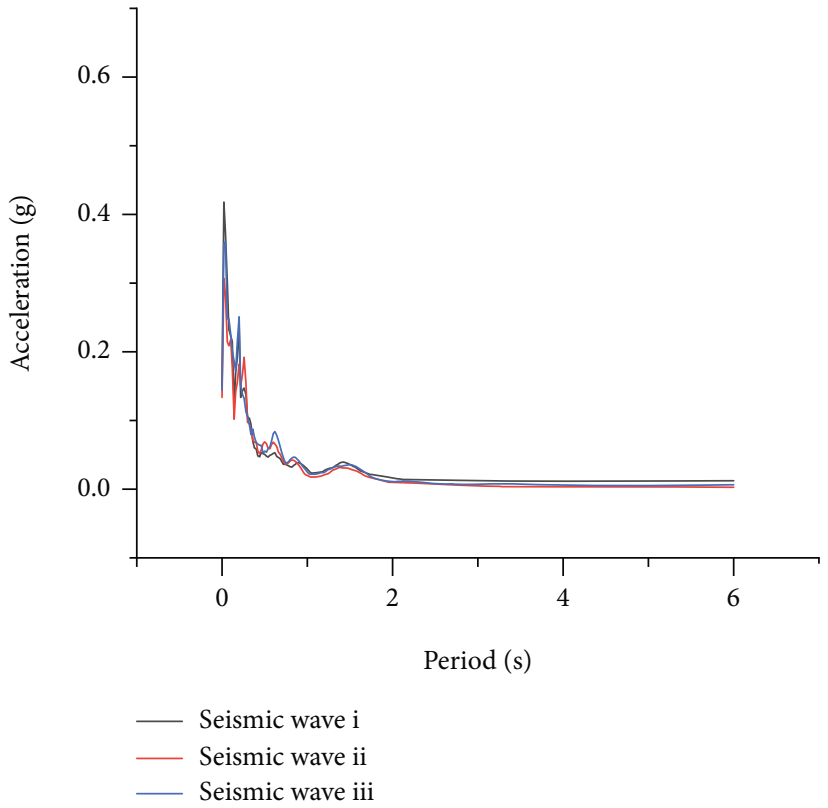

FIgURE 3: Seismic response spectrum diagram.

TABLE 3: The first six order modal periods of the structure with different soil properties.

\begin{tabular}{lccc}
\hline Mode & $\begin{array}{c}\text { Considering SSI } \\
\text { effect (hard soil) (s) }\end{array}$ & $\begin{array}{c}\text { Considering SSI } \\
\text { effect (soft soil) }\end{array}$ & $\begin{array}{c}\text { Regardless of } \\
\text { the SSI effect (s) }\end{array}$ \\
\hline 1 & 1.643 & 1.704 & 1.302 \\
2 & 1.524 & 1.649 & 1.101 \\
3 & 1.355 & 1.564 & 0.713 \\
4 & 1.311 & 1.422 & 0.609 \\
5 & 1.265 & 1.349 & 0.611 \\
6 & 1.182 & 1.286 & 0.588 \\
\hline
\end{tabular}




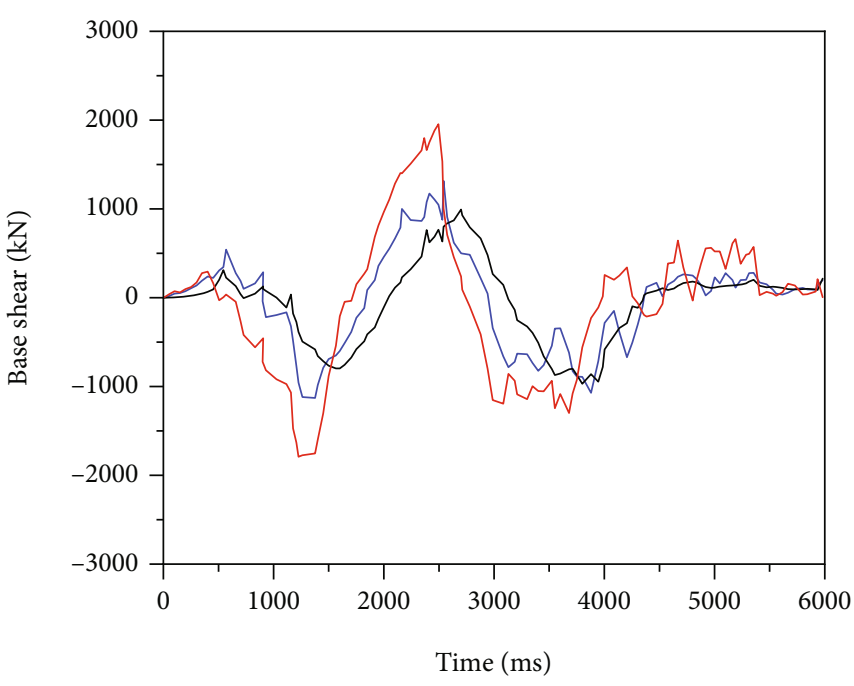

(a) Seismic wave $\mathrm{i}$

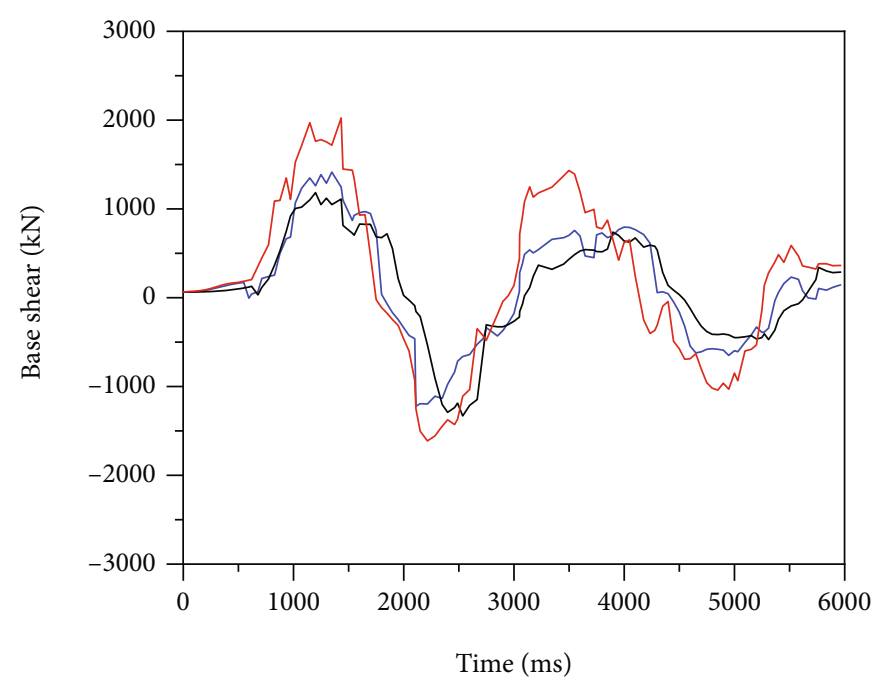

(b) Seismic wave ii

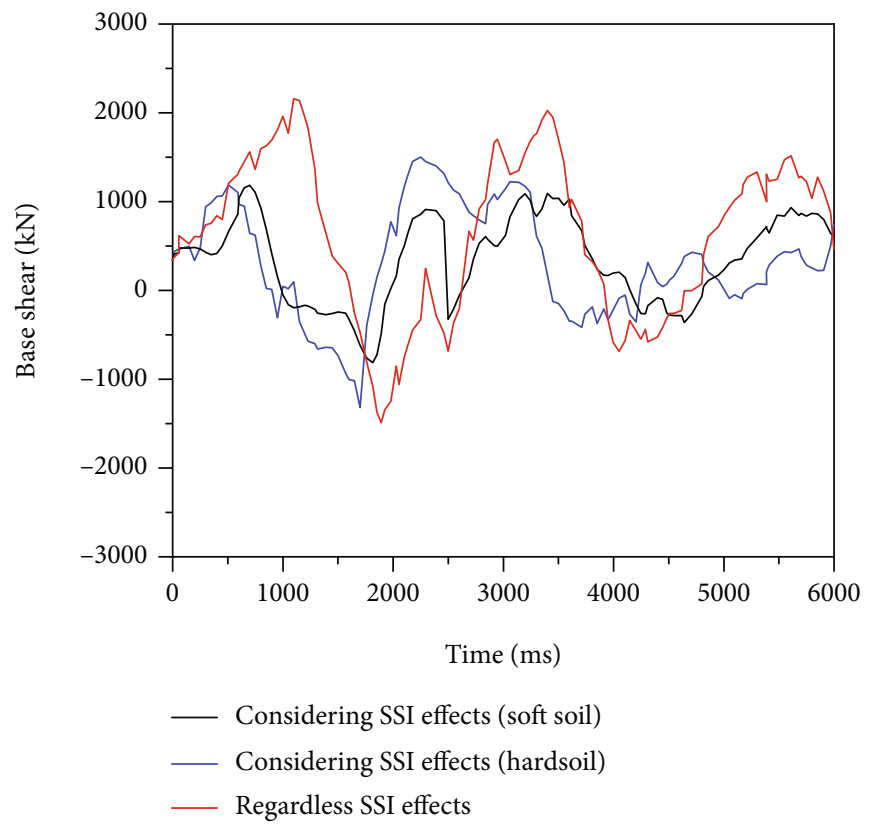

(c) Seismic wave iii

FIgURE 4: Comparison of base shear with different soil properties under the effect of ground motion.

out. At the same time, the seismic frequency in this area has also increased sharply [3-5]. For example [6-9], the Junlian earthquake with magnitude 4.9, Xingwen Earthquake with magnitude 5.7, Weiyuan earthquake with magnitude 5.4 occurring in Sichuan Basin, and Red Dee earthquake with magnitude 4.2 occurring in Western Canada Basin have been proved to have a time and space correlation with the fracturing operation in the nearby horizontal well. Based on the above, it is particularly important to take necessary seismic isolation measures for industrial ancillary buildings. Since hydraulic fracturing causes vibration in the depth of the formation to cause seismic, the energy of the earthquake is transmitted to the building through the soil, so the seismic structure system considering the soil-structural interaction is more in line with the actual situation. ATC-40 [10]estab- lished a soil spring model and defined the damping model to consider the SSI effect. Bi et al. [11] studied the comprehensive effects of spatial variation of ground motion, local site amplification, and SSI on bridge response and estimated the required separation distance that modular expansion joints must provide to avoid seismic impact. The minimum total clearance between two adjacent decks or between deck and adjacent abutment to prevent seismic shock was estimated by using the standard random vibration method to estimate the peak structural response. Numerical results show that SSI had significant influence on structural response and cannot be ignored. In [12], considering soilstructure interaction, pushover method, natural frequency, vertex limit displacement, and plastic hinge expansion were used to analyze the frame structure of a 6-story office 


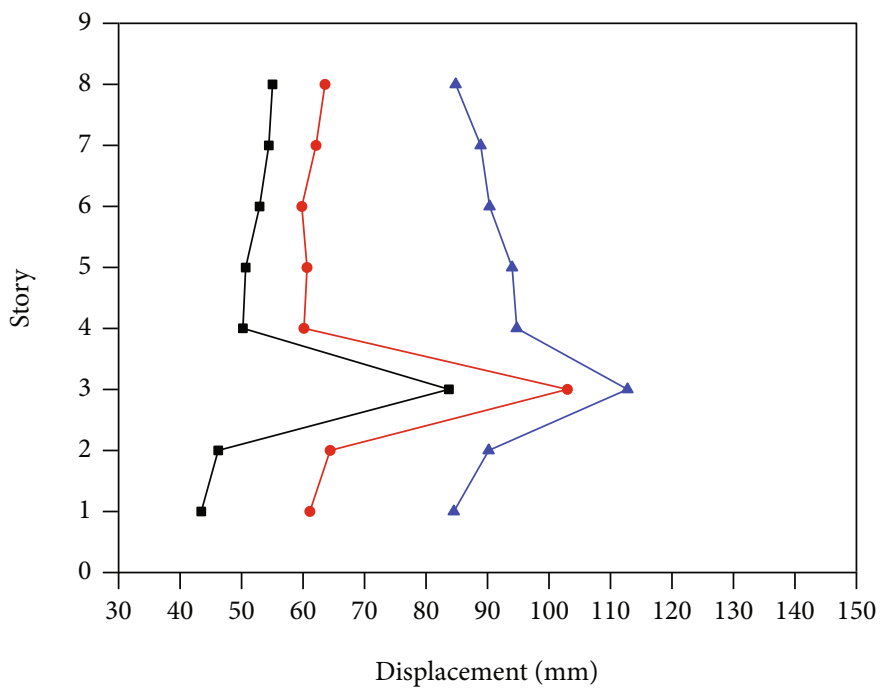

(a) Seismic wave i

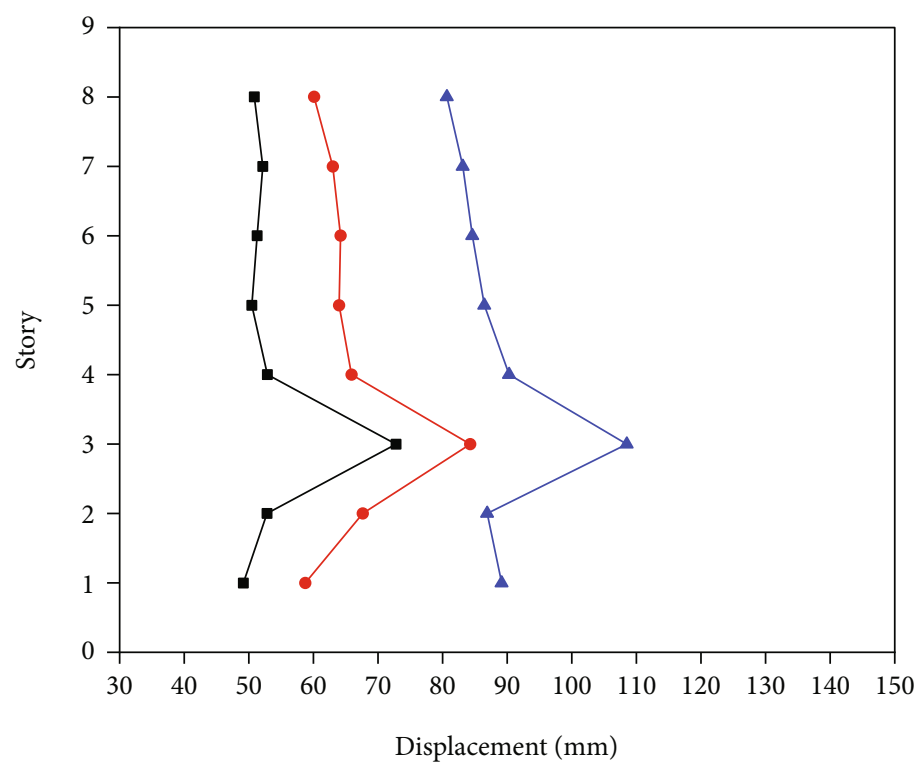

(b) Seismic wave ii

Figure 5: Continued. 


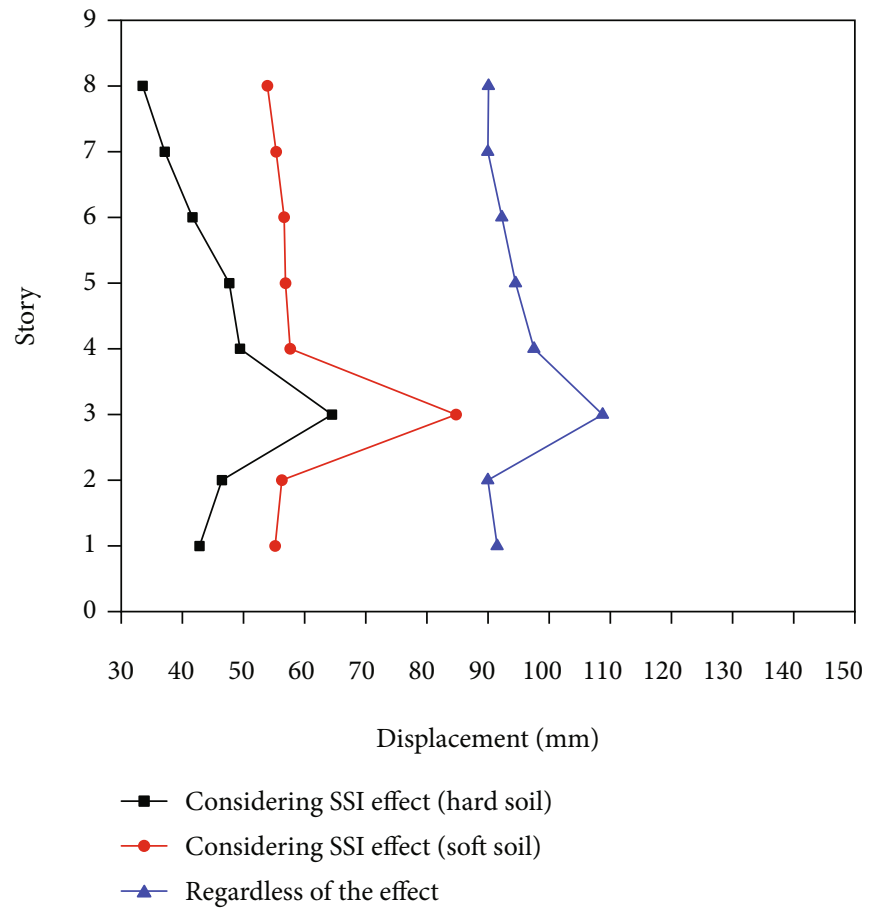

(c) Seismic wave iii

FIGURE 5: Comparison of story displacement with different soil properties under the effect of ground motion.

building under the assumption of rigid foundation. The results show that considering soil-structure interaction, the natural vibration period of RC frame structure became longer, and more hinges appeared at the bottom of column with the increase of vertex displacement. In [13, 14], a simple three-dimensional model was presented for the linear interaction analysis of fully coupled soil-pile-structure system under harmonic shear seismic waves. By comparing the amplification of coupling system with the amplitude amplification of free site surface response to bedrock vibration, it was proved that the dynamic interaction of coupling system cannot be neglected in the dynamic analysis and design of stacking structure. This was the basis for detailed numerical analysis and experimental study of soil-pile-structure dynamic interaction. Grange et al. [15] proposed a numerical strategy to simulate a three-hole viaduct made of prestressed concrete, showing the influence of soil-structure interaction (SSI). The research results show that SSI was a complex phenomenon and caused the structure of the displacement and internal force, and it was difficult to predict the displacement and internal force and linear method. At the same time, the influence of near-fault vertical ground motion on building seismic response had also become an important consideration [16]. Liu et al. [17] used isolators with quasizero stiffness and vertical dampers to control vertical earthquakes near faults. The results show that increasing the vertical period and damping ratio could make the vertical isolated structure perform well in reducing the swaying response of the structure.

The above research focuses on the seismic and isolation system of the damage effect of hydraulic fracturing on underground rock strata and the structural seismic effect, while the research on the soil structure seismic effect caused by hydraulic fracturing is very limited. Therefore, a seismic isolation structure model considering the SSI effect is established in this paper to reveal the seismic response of the isolated structure in the case of earthquakes caused by hydraulic fracturing.

\section{The Finite Element Model}

2.1. Project Overview. An 8-story seismic isolation frame structure model is established. The site fortification intensity is 8 degrees, the site category is second class, and the design earthquake group is second group. In the frame structure system, the seismic isolation layer is on top of the second story. The column concrete strength model is C40, the beam concrete strength model is C30, the longitudinal reinforcement model is HRB400 with a design value of tensile strength and compressive strength is $360 \mathrm{~N} / \mathrm{mm}^{2}$, and the stirrup model is HRB335 with a design value of $270 \mathrm{~N} / \mathrm{mm}^{2}$ for tensile and compressive strength. The raft foundation was adopted, the upper structure damping ratio is 0.05 , the soil damping ratio of the foundation is 0.1 [18], and Rayleigh damping is adopted. Because even the shear waves are assumed to propagate vertically in the soil, kinematic interactions will occur in structures with embedded foundations, and this paper used two different soil layers of the raft foundation to simulate the seismic response of the structure encountering the earthquake. Figure 2 shows the three-dimensional finite element model of the structure. Table 1 shows the parameters of soil below the foundation, number 1 represents the soft soil layer, and number 2 represents the hard soil layer. Considering the unconfined 
S, Mises

Multiple section points

(avg: 75\%)

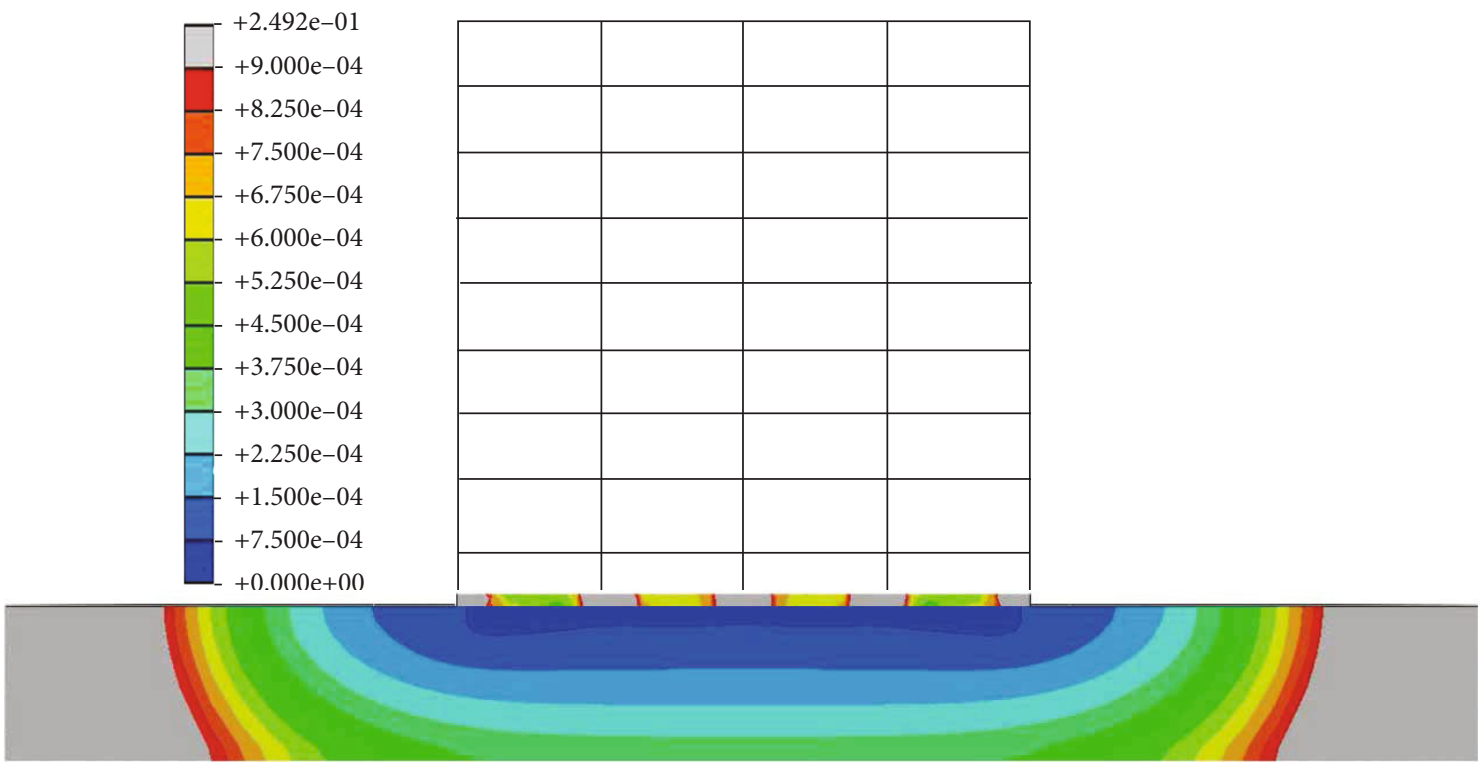

(a) Considering SSI effect (hard soil)

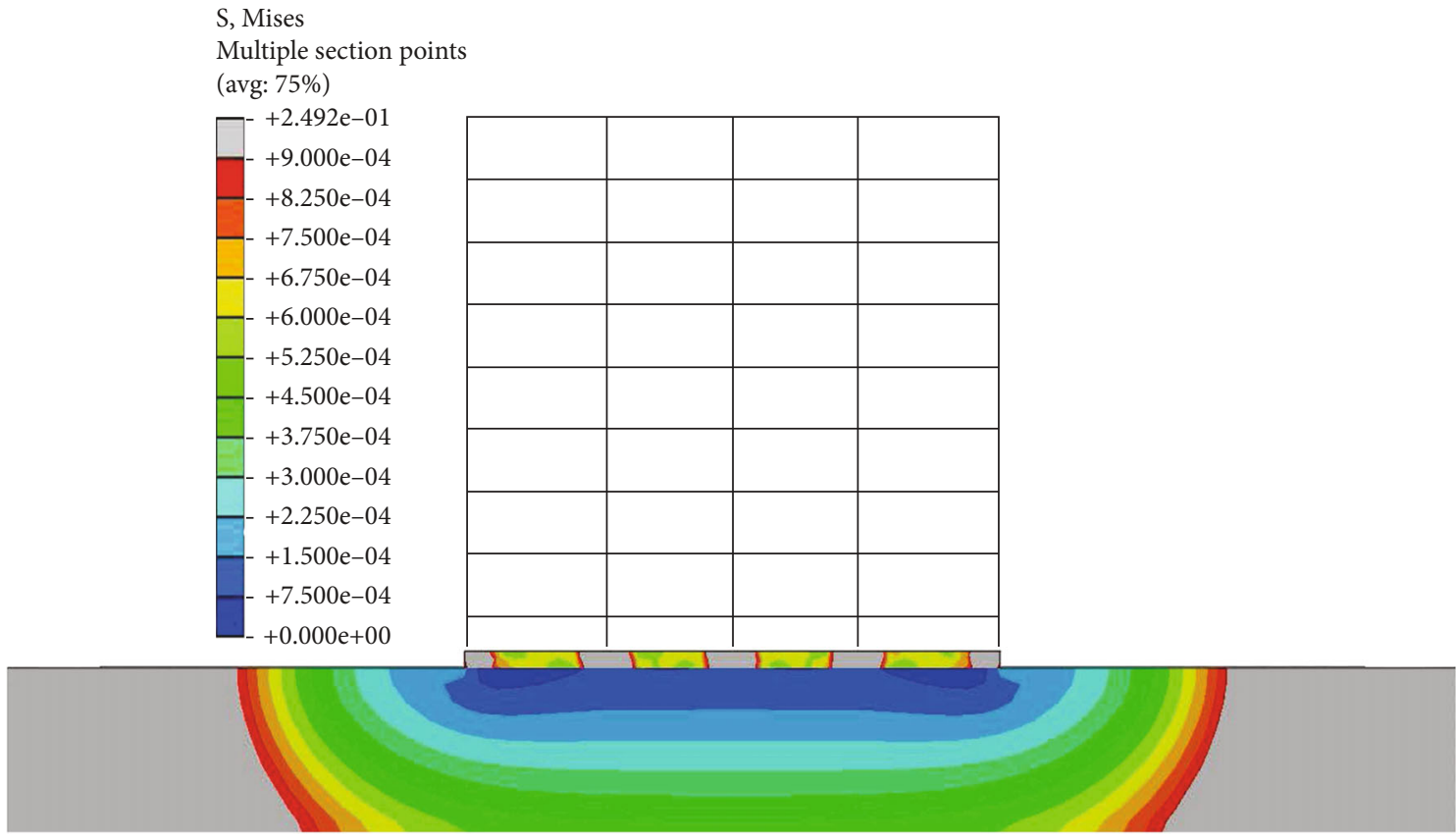

(b) Considering SSI effect (soft soil)

FIGURE 6: Stress of soil with different soil properties under ground motion.

condition of soil, Young's modulus was adopted. Table 2 lists the cohesive boundary parameters.

During the simulation, the beams and columns of the model adopt beam units, the floor slab adopts shell units, the foundation adopts solid units, they are bound by the tie, and coacting nodes adopt a coupling connection. The simulated soil is filled in a rectangle about 16 times the square plan, $400 \mathrm{~m}$ in length, $300 \mathrm{~m}$ in width, and $30 \mathrm{~m}$ in depth. The viscoelastic boundary was used to absorb the seismic wave at the boundary of the soil [19]. Seismic waves are applied at the bottom of the bedrock to produce seismic effects on the structure and soil. Nonlinear springs were used to simulate seismic isolation bearings [20].

2.2. Ground Motion Data Sets. The maximum fortification acceleration of the site is $0.2 \mathrm{~g}$, and the impact coefficient of fortification is 0.45 . The acoustic emission recorder could collect the acoustic emission parameters in the process of 


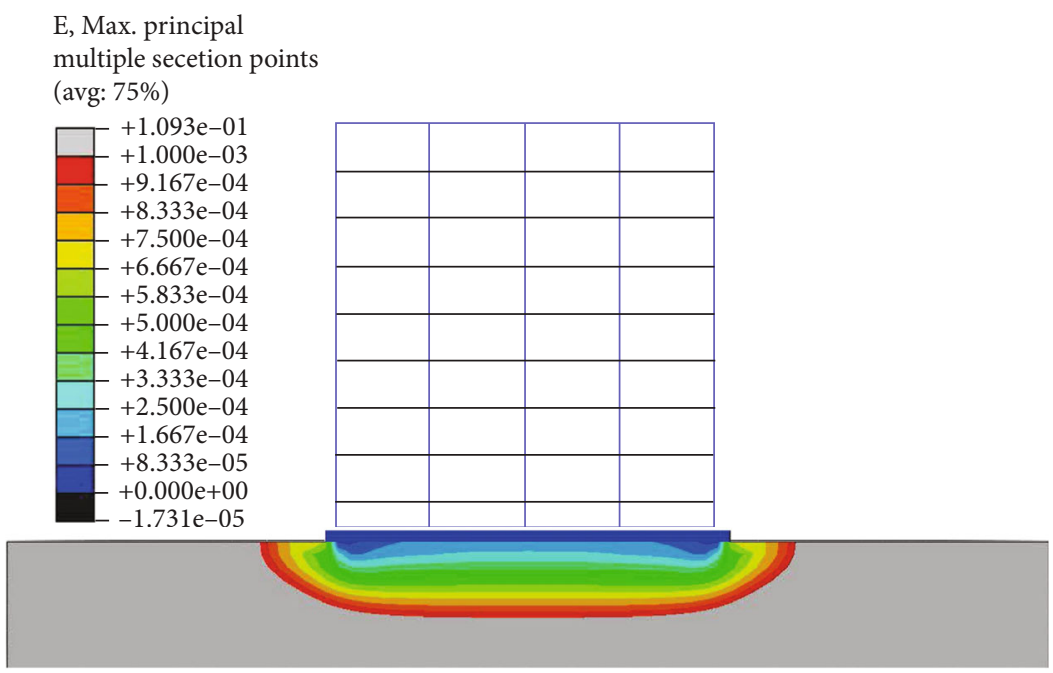

(a) Considering SSI effect (hard soil)

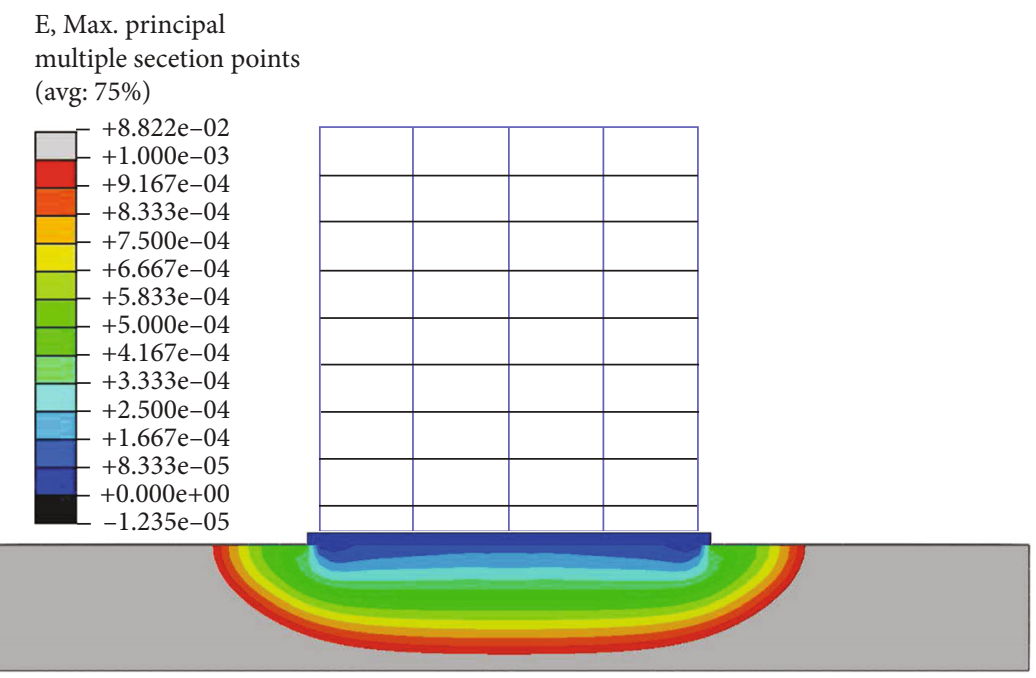

(b) Considering SSI effect (soft soil)

FIGURE 7: Strain of soil with different soil properties under the effect of ground motion.

TABLE 4: The first six order modal periods of the structure with different soil properties with different foundation buried depths.

\begin{tabular}{lccc}
\hline Mode & $\begin{array}{c}\text { Shallow-buried } \\
\text { foundation (s) }\end{array}$ & $\begin{array}{c}\text { Deep-buried } \\
\text { foundation }(\mathrm{s})\end{array}$ & $\begin{array}{c}\text { Regardless of the } \\
\text { SSI effect }(\mathrm{s})\end{array}$ \\
\hline 1 & 3.631 & 3.503 & 3.225 \\
2 & 3.013 & 2.822 & 2.737 \\
3 & 2.571 & 2.419 & 2.333 \\
4 & 2.402 & 2.404 & 2.171 \\
5 & 1.833 & 1.835 & 1.524 \\
6 & 1.721 & 1.721 & 1.325 \\
\hline
\end{tabular}

reservoir rock fracture. By simplifying the waveform of parameters such as energy, amplitude, duration, and rise time, it could simulate the amplitude, frequency, phase, and other parameters of seismic wave generated by different lithology, summarize the characteristics of fracture signal, and establish the template of seismic signal generated by dif- ferent types of rock sample fracture. For example, Zhou et al. [21] measured the full-field deformation data of granite samples under different loading amplitudes, obtained the threshold value of rock breakage under ultrasonic vibration, and reproduced the process of crack initiation and propagation through numerical simulation. In the process of hydraulic fracturing, the small fracture of soil and rock will gradually become larger fracture [22]. Compared with the natural seismic wave, the vibration wave generated by hydraulic fracturing would migrate to the low-frequency part with the aggregation of microfracture and the expansion of crack, and the larger the crack, the lower the frequency. Therefore, the frequency of source signal decreased exponentially with the increase of radius [23]. In this study, according to the hydraulic fracturing sites monitored by acoustic emission recorder, three relatively stable vibration energy waves were selected to simulate the energy release of seismic waves, which were denoted as seismic waves $i$, seismic wave ii, and seismic wave iii, respectively. At the 


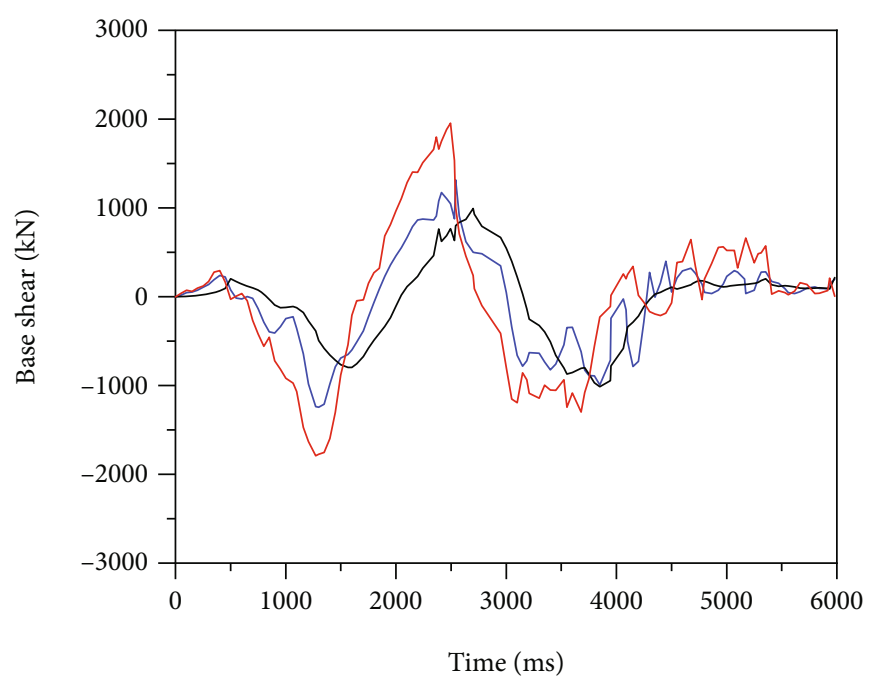

(a) Seismic wave $\mathrm{i}$

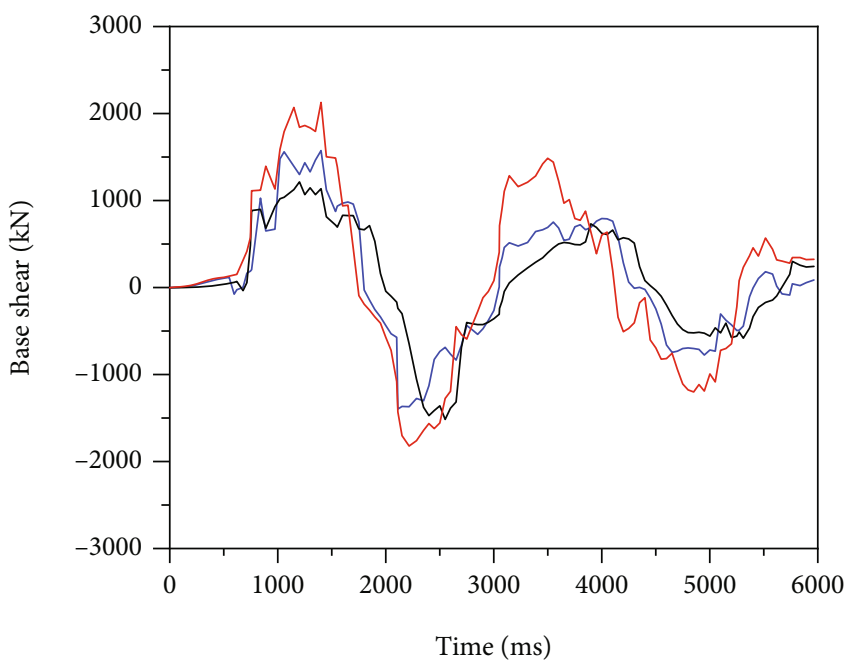

(b) Seismic wave ii

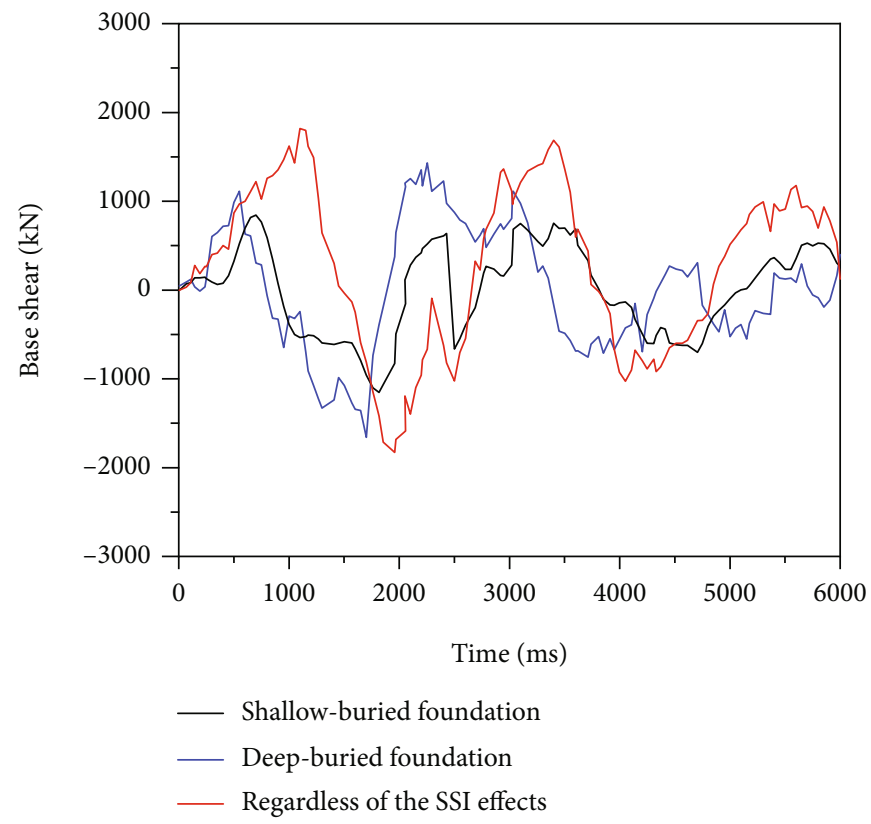

(c) Seismic wave iii

FIGURE 8: Comparison of base shear with the different buried depth of foundation under the effect of ground motion.

same time, soil liquefaction had been recognized as one of the factors causing natural disasters and engineering damage in earthquake disasters [24-27], so the seepage effect of rock bottom fluid on hydraulic fracturing fractures was also considered. Figure 3 shows the response spectra of the three seismic waves.

\section{Seismic Response of the Isolated Structure}

3.1. Seismic Response of the Isolated Structure with Different Soils. The modal periods of the isolated structure when the basement adopted different properties of soil are shown in Table 3.

It can be seen from Table 3 that for the soft soil basement, the natural period of the isolated building was greater than that of the hard soil basement. The period of the overall system was the smallest without considering the SSI effect. When considering the SSI effect, the harder the soil is, and the larger the shear wave speed of the soil is. By setting different soil shear wave speeds, the soil with different hard degrees was simulated, and the corresponding different periods were obtained. It was found that the effect of softness on the period value became more and more obvious, indicating that the soil has the effect of seismic isolation. The elastoplastic time history analysis of the structure under three kinds of rare earthquakes was carried out, and the corresponding base shear force of the structure with different properties of soil is shown in Figure 4.

It can be seen that without considering the SSI effect, the base shear force was significantly greater than that 


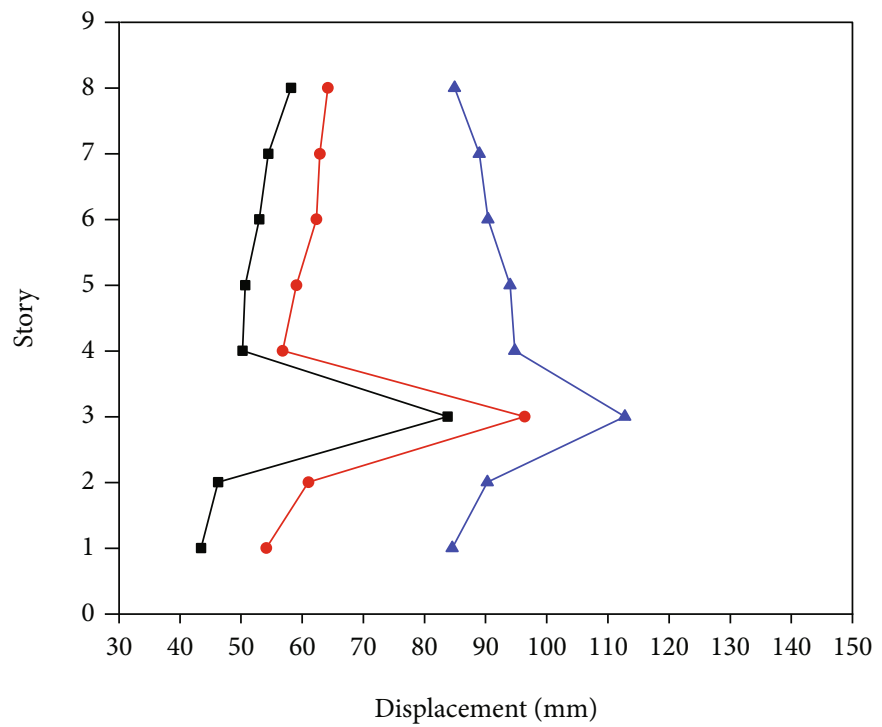

(a) Seismic wave $\mathrm{i}$

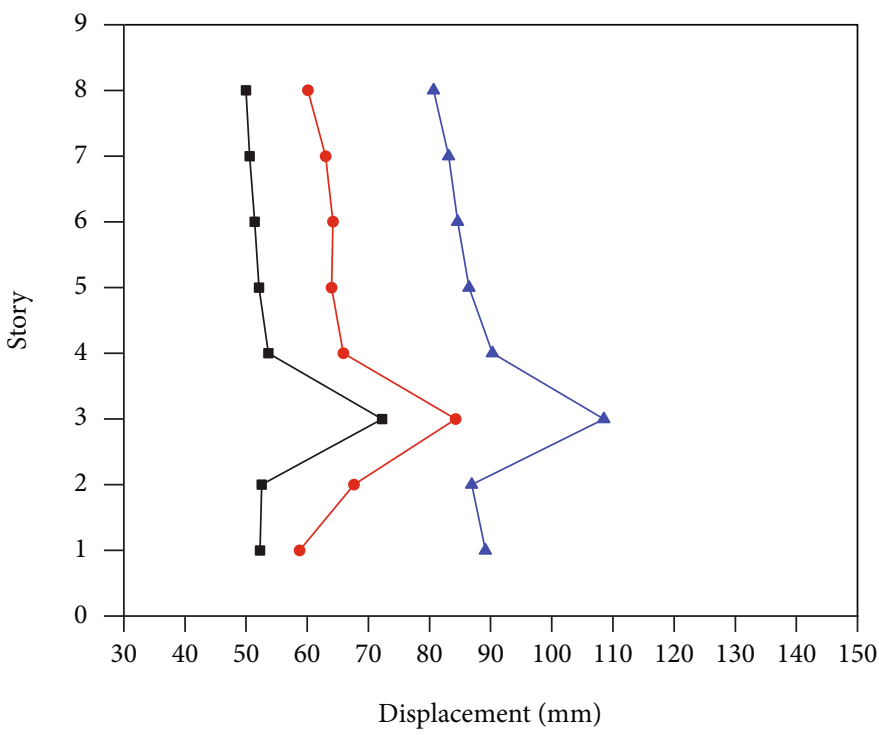

(b) Seismic wave ii

Figure 9: Continued. 


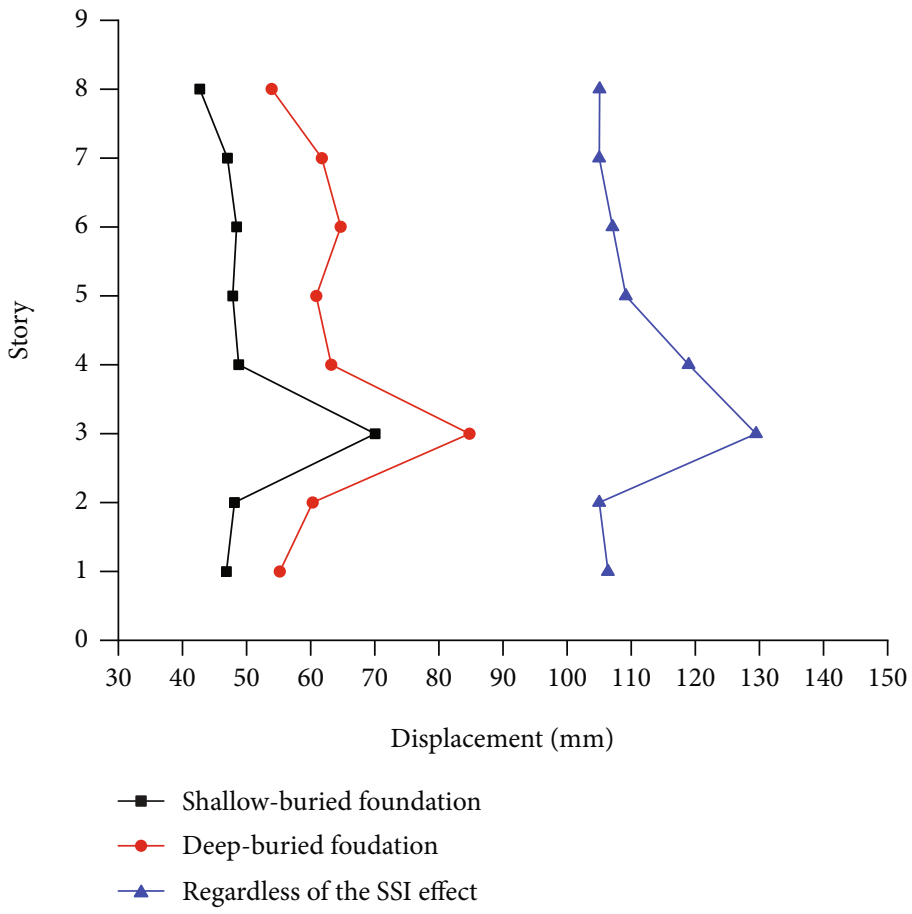

(c) Seismic wave iii

Figure 9: Comparison of story displacement with the different buried depth of foundation under the effect of ground motion.

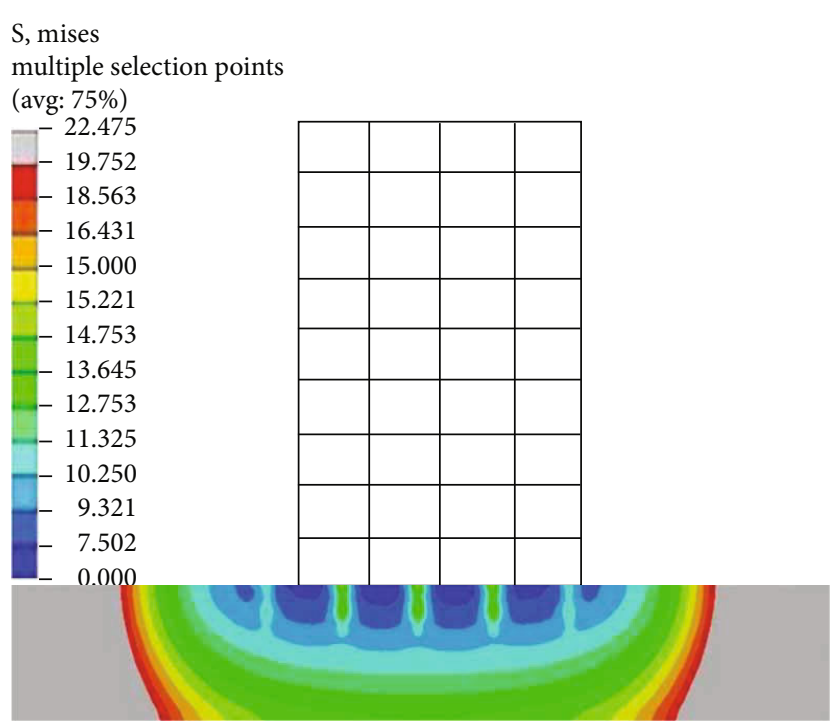

(a) Shallow-buried foundation

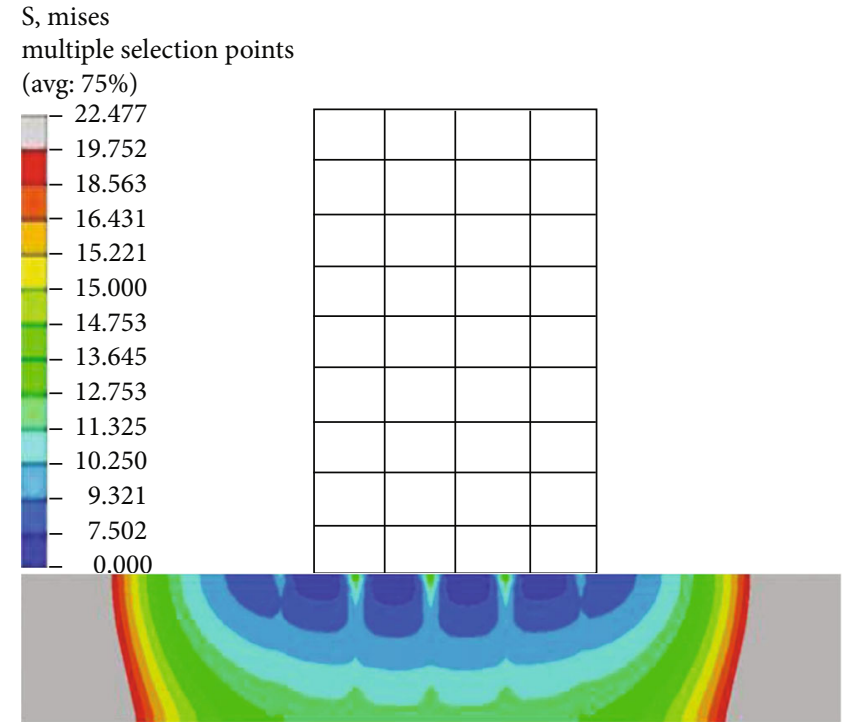

(b) Deep-buried foundation

Figure 10: Stress of soil with the different buried depth of foundation under the effect of ground motion.

considering SSI, and when the base was made of hard soil, the shear force was greater than that of soft soil. The story displacement under the condition of three kinds of seismic waves is shown in Figure 5.

As shown in Figure 5, under conditions of three kinds of seismic waves, the seismic response analysis of the midstory isolated structure considering the SSI effect was conducted; the results showed that the displacement of the layer 3 increased dramatically under different ground motion effects, which is because the isolation layer in the structural model is located at the third story, and the seismic isolation bearing used to simulate the seismic isolation layer deformed greatly. Without considering the SSI effect, the story displacement was obviously greater than considering the SSI, indicating that the isolation structure considering the SSI effect has a better shock absorption effect. However, under the seismic wave, the different softness of the foundation soil made the filtering effect of the midstory isolated structure considering the SSI effect obviously different. When hard soil was used as the base, the interlayer displacement of the 


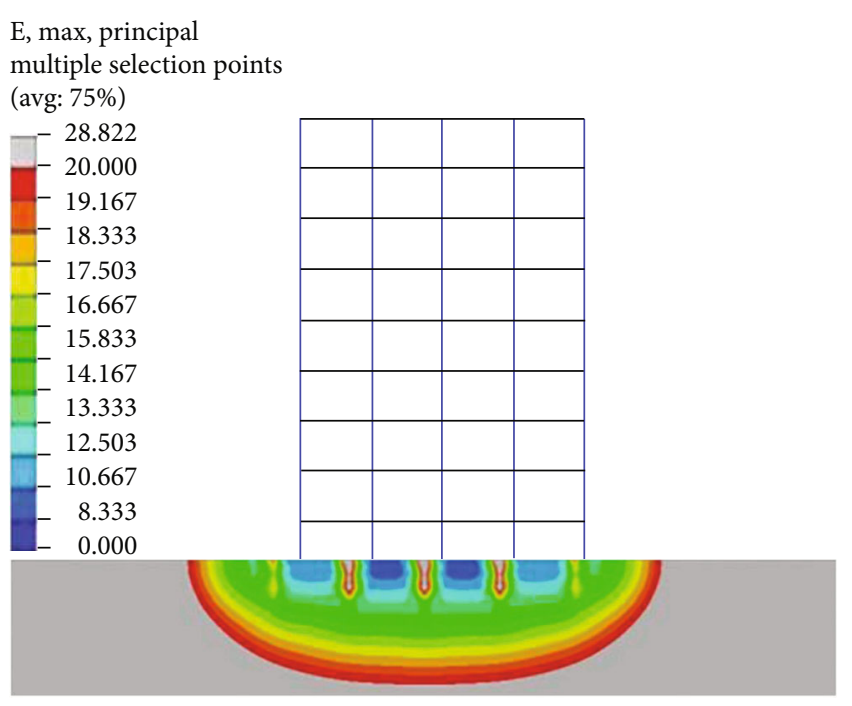

(a) Shallow-buried foundation

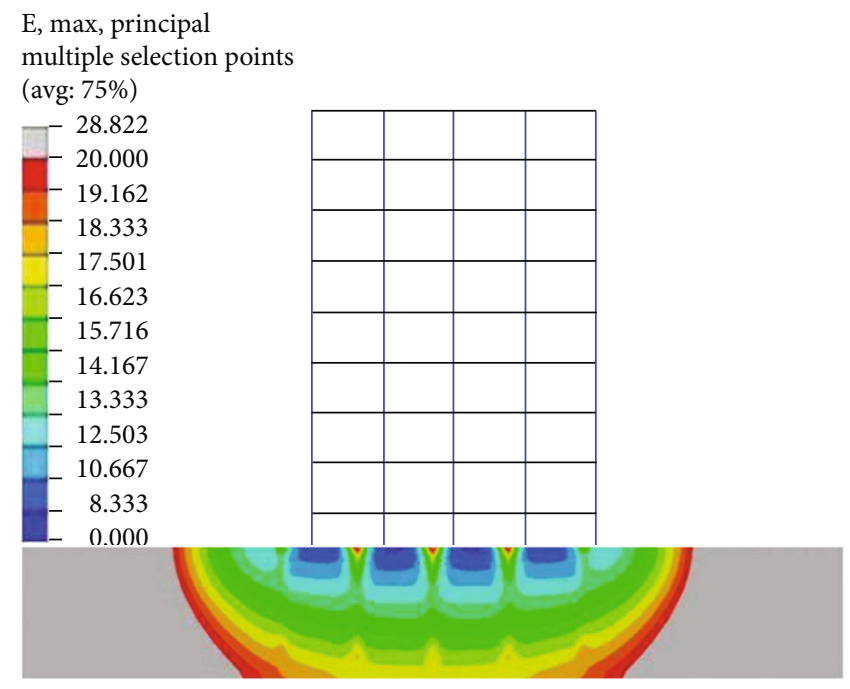

(b) Deep-buried foundation

Figure 11: Strain of soil with different buried depth of foundation under ground motion.

structure was larger than that of soft soil, which indicates that the filtering effect of soft soil is obviously better than that of hard soil. Under the effect of ground motion, the stress and strain of soils with different properties are shown in Figures 6 and 7.

As shown in Figures 6 and 7, when soils with different properties were used as the basement, the stress and strain of the soil were different. As the stiffness of the soil increased, the stress and strain of the soil layer in the basement became greater.

3.2. Seismic Response of the Isolated Structure with Different Foundation Burial Depths. Considering the SSI effect, the modal period of the isolated structure with different foundation buried depths is shown in Table 4, in which the buried depth of the top surface of the shallow buried foundation is $50 \mathrm{~cm}$, and that of the deep buried foundation is $150 \mathrm{~cm}$.

According to Table 4, considering the SSI effect, the period of the first two order modes of the deep-buried foundation was smaller than that of the shallow-buried foundation, and the period value of the higher-order structure was similar. The seismic responses of foundations with different buried depths under three seismic waves are shown in Figure 8.

Figures 6 and 7 show that without considering the SSI effect, the seismic response was significantly greater than that considering the SSI effect, and the base shear value of the structure with the shallow buried foundation was lower than that of the deeply buried foundation, this is because that the deep-buried foundation provided more constraints around the foundation on the structure, strengthening the constraint effect on the structure, reducing the rotation of the foundation and increasing the acceleration transmitted. Under three seismic waves, displacement responses of structures with different foundation burial depths are shown in Figure 9.

Figures 8 and 9 show that without considering SSI, the structural displacement response was significantly larger than that considering SSI, and for the deeply buried foundation, the displacement of each layer of the structure was larger than that shallow buried foundation. For the different buried depths of the foundation, the stress of the structure and stress and strain of soil under the effect of ground motion are shown in Figures 10 and 11.

As Figures 10 and 11 show, under the action of raft foundation, there was little difference in stress between the structure of deeply buried and shallow buried foundations, while compared with the shallow buried foundation, the soil stress and strain of deep-buried foundation were greater, and the action range was wider, which means that the stress field and strain field were different for different foundation.

\section{Conclusion}

In this paper, the vibration generated by hydraulic fracturing is used to simulate the earthquake, the isolation structure model considering SSI effect is established, the nonlinear response and seismic response law of the lower isolation structure are studied and analyzed, and the following conclusions are drawn:

(1) The fluid in the hydraulic fracturing effect spread to the soil, and make the role of soft soil has absorption dissipation of earthquake energy

(2) Considering the SSI effect, when hard soil was used as the basement, the structural base shear force and story displacements were larger than that of soft soil

(3) Under different seismic waves, the seismic response considering the SSI effect is smaller than that without considering the SSI

(4) Considering the SSI effect, for the deeply buried foundation, the structural base shear force and story displacements were larger than the shallow buried foundation 


\section{Data Availability}

All data included in this study are available upon request by contact with the corresponding author.

\section{Conflicts of Interest}

The authors declare that there is no conflict of interests regarding the publication of this paper.

\section{Acknowledgments}

The writers gratefully acknowledge the financial support of the Scientific Research Foundation of Education Department of Yunnan Province, no. 2021Y226.

\section{References}

[1] G. M. Atkinson, D. W. Eaton, H. Ghofrani et al., "Hydraulic fracturing and seismicity in the western Canada sedimentary basin," Seismological Research Letters, vol. 87, no. 3, pp. 631$647,2016$.

[2] R. Schultz, R. Wang, Y. J. Gu, K. Haug, and G. Atkinson, “A seismological overview of the induced earthquakes in the Duvernay play near Fox Creek, Alberta," Journal of Geophysical Research Solid Earth, vol. 122, no. 1, pp. 492-505, 2017.

[3] Y. Tan, J. Hu, H. Zhang et al., "Hydraulic fracturing induced seismicity in the southern Sichuan Basin due to fluid diffusion inferred from seismic and injection data analysis," Geophysical Research Letters, vol. 47, no. 4, 2020.

[4] M. Wang, H. Yang, L. Fang et al., "Shallow faults reactivated by hydraulic fracturing: the 2019 Weiyuan earthquake sequences in Sichuan, China," Seismological Research Letters, vol. 91, no. 6, pp. 3171-3181, 2020.

[5] H. Yang, P. Zhou, N. Fang et al., "A shallow shock: the 25 February 2019 ML 4.9 earthquake in the Weiyuan shale gas field in Sichuan, China," Seismological Research Letters, vol. 91, no. 6, pp. 3182-3194, 2020.

[6] X. Lei, D. Huang, J. Su et al., "Fault reactivation and earthquakes with magnitudes of up to Mw4.7 induced by shalegas hydraulic fracturing in Sichuan Basin, China," Scientific Reports, vol. 7, no. 1, p. 7971, 2017.

[7] X. Lei, Z. Wang, and J. Su, “The December 2018 ML 5.7 and January 2019 ML 5.3 earthquakes in south Sichuan Basin induced by shale gas hydraulic fracturing," Seismological Research Letters, vol. 90, no. 3, pp. 1099-1110, 2019.

[8] X. Lei, J. Su, and Z. Wang, "Growing seismicity in the Sichuan Basin and its association with industrial activities," Science China Earth Sciences, vol. 63, no. 11, pp. 1633-1660, 2020.

[9] R. Schultz and R. Wang, "Newly emerging cases of hydraulic fracturing induced seismicity in the Duvernay East Shale Basin," Tectonophysics, vol. 779, article 228393, 2020.

[10] C. D. Comartin, R. W. Niewiarowski, S. A. Freeman, and F. M. Turner, "Seismic evaluation and retrofit of concrete buildings: a practical overview of theATC 40document," Earthquake Spectra, vol. 16, no. 1, pp. 241-261, 2000.

[11] K. Bi, H. Hong, and N. Chouw, "Influence of ground motion spatial variation, site condition and SSI on the required separation distances of bridge structures to avoid seismic pounding," Earthquake Engineering \& Structural Dynamics, vol. 40, no. 9, pp. 1027-1043, 2011.
[12] Z. Wangxi, L. Rui, C. Yadong et al., "Study on aseismic performance of reinforced concrete frame structures considering the soil-footing-structure interaction," Earthquake Engineering and Engineering Vibration, vol. 39, no. 4, pp. 86-97, 2019.

[13] S. Shang, X. Zou, and W. Cao, "Experimental investigation on soil-structure interaction of steel frame-raft foundation," Journal of Building Structures, vol. 33, no. 9, pp. 74-80, 2012.

[14] H. Ren, S.-P. Shang, G. Li, and J. Yu, "Simplified analysis on dynamic linear soil-pile-structure interaction," Journal of Hunan University, vol. 34, no. 11, pp. 6-11, 2007.

[15] S. Grange, L. Botrugno, P. Kotronis, and C. Tamagnini, "The effects of soil-structure interaction on a reinforced concrete viaduct," Earthquake Engineering \& Structural Dynamics, vol. 40, no. 1, pp. 93-105, 2011.

[16] D. Liu, Y. Liu, D. Sheng, and W. Liao, "Seismic response analysis of an isolated structure with QZS under near-fault vertical earthquakes," Shock and Vibration, vol. 2018, Article ID 9149721, 12 pages, 2018.

[17] D. Liu, Y. Zhang, S. Fang, and Y. Liu, "Horizontal-verticalrocking coupled response analysis of vertical seismic isolated structure under near-fault earthquakes," Shock and Vibration, vol. 2020, Article ID 6519808, 10 pages, 2020.

[18] W. Chen, L. W. Kong, and J. Q. Zhu, "A simple method to approximately determine the damping ratio of soils," Rock and Soil Mechanics, vol. 28, pp. 789-791, 2007.

[19] J.-T He, H. Ma, B.-Y. Zhang, and H.-Q. Chen, "Method and realization of seismic motion input of viscous-spring boundary," Journal of Hydraulic Engineering, vol. 41, no. 8, pp. 960-969, 2010.

[20] R. Lin, W. Liu, S. Wang, and D. Du, "Numerical simulation of nonlinear characteristics of isolation bearing," World Earthquake Engineering, vol. 30, no. 3, pp. 240-246, 2014.

[21] Y. Zhou, D. Zhao, B. Li, H. Wang, Q. Tang, and Z. Zhang, "Fatigue damage mechanism and deformation behaviour of granite under ultrahigh-frequency cyclic loading conditions," Rock Mechanics and Rock Engineering, vol. 54, no. 9, pp. 4723-4739, 2021.

[22] G. Nolet, Quantitative Seismology, Theory and Methods, Elsevier, 1980.

[23] E. J. Kaiser, A Study of Acoustic Phenomena in Tensile Test [Ph.D. thesis], Technische Hochschule München, Munich, Germany, 1959.

[24] Y. Zhang, Y. Xie, Y. Zhang, J. Qiu, and S. Wu, "The adoption of deep neural network (DNN) to the prediction of soil liquefaction based on shear wave velocity," Bulletin of Engineering Geology and the Environment, vol. 80, no. 6, pp. 5053-5060, 2021.

[25] X. Liu, D. Fan, Y. Tan et al., "Failure evolution and instability mechanism of surrounding rock for close-distance parallel chambers with super-large section in deep coal mines," International Journal of Geomechanics, vol. 21, no. 5, p. 04021049 , 2021.

[26] X. Liu, D. Fan, Y. Tan et al., "New detecting method on the connecting fractured zone above the coal face and a case study," Rock Mechanics and Rock Engineering, vol. 54, no. 8, pp. 4379-4391, 2021.

[27] X. Liu, S. Song, Y. Tan et al., "Similar simulation study on the deformation and failure of surrounding rock of a large section chamber group under dynamic loading," International Journal of Mining Science and Technology, vol. 31, no. 3, pp. 495-505, 2021. 